\title{
Cervical Cancer Screening: Recommendations for Muslim Societies
}

\author{
Nahid Khodakarami ${ }^{1}$, Farah Farzaneh², Parvin Yavari³ ${ }^{3}$ Mohamad Esmaeil \\ Akbari ${ }^{4 *}$
}

\begin{abstract}
Background: The overall cervical cancer incidence rate is low in Iran; however, because of a higher risk of death for cervical cancer, a disease that kills women in middle age, a cervical cancer control program is needed. The aim of this study was to provide consensus recommendation for cervical cancer prevention in Iran and other Muslim societies with low incidences of cervical cancer. Materials and Methods: Through a practical guideline development cycle, we developed six questions that were relevant to produce the recommendation. We reviewed 190 full text records of cervical cancer in Iran (1971 to 2013) of which 13 articles were related to the data needed to answer the recommendation questions. We also reviewed World Health Organization, IARC, GLOBOCAN report, Iran Ministry of Health cancer registry report and 8 available foreign countries guidelines. Lastly, we also evaluated the Pap smear results of 825 women who participated in the Iranian HPV survey, of whom 328 were followed-up after a 5-year interval. Results: The obtained data highlighted the burden of HPV and cervical cancer situation in Iran. Experts emphasized the necessity of a cervical cancer screening program for Iranian women, and recommended an organized screening program with a cytological evaluation (Pap smear) that would start at the age of 30 years, repeated every 5 years, and end at the age of 69 years. Meanwhile, there is no need for screening among women with a hysterectomy, and screening should be postponed to post-partum among pregnant women. Conclusions: An organized cervical cancer screening is a necessity for Iran as more than 500-900 women in middle age diagnosed with an invasive cervical cancer every year cannot be ignored. This recommendation should be taken into account by the National Health System of Iran and Muslim countries with shared culture and behavior patterns. CUBA HPV test could be consideration in countries Muslim country with appropriate budget, resources and facility.
\end{abstract}

Keywords: Guideline - cervical cancer - screening - pap smear - Iran - muslim societies

Asian Pac J Cancer Prev, 17 (1), 239-247

\section{Introduction}

Cervical cancer in Iran and Muslim Countries has been reported less commonly compared to some of the countries in the world, it has had the 11th rank among the most common women's cancers in 2009. In 2009, 558 new cases of cervical cancer and 286 related deaths resulted from that have been recorded (Forman et al., 2012; I. M. o. Health, 2012).

Research indicates that more than $50 \%$ of women with cervical cancer have never been screened, and $10 \%$ of them had not been screened in the past 5 years prior to their cancer(United States. Department of Health and Human Services., 2001). Countries with organized screening programs are able to reduce cervical cancer significantly (Aminisani, Armstrong, and Canfell, 2012; Castellsague et al., 2009).

The early published papers about cervical cancer in Iran reported a low incidence in Iran, when cervical cytology evaluation was facilitated for the women who referred to the family planning services in 1970 (Behmard, Taherzadeh and Gondos, 1977; Habibi, 1965; 1970; 1971). The first organized cervical cancer program guideline was developed in 1990, and the cervical cancer screening came to the public health services. According to this national guideline, all 20-65 year old married women referring to the public health clinics to have a general health checkup or to use maternal child health and family planning services were annually invited for a cytological screening test. The women who had 3 negative tests in a row, were invited for a screening test every 3 years. (M. o. Health, 2001).

In 1993, a cost-effectiveness analysis study was conducted by the Iranian Ministry of Health. The results of 830,000 conventional pap smears detected 1213 abnormal cytological results. Follow up of these cases led to the

${ }^{1}$ Cancer Research Center Shahid Beheshti University of Medical Sciences Tehran, ${ }^{2}$ Obstetrician and Gynecology Department, Imam Hossein Hospital, ${ }^{3}$ Department of Health \& Community Medicine, School of Medicine, ${ }^{4}$ Corresponding Author: Cancer Research Center, Shahid Beheshti University of Medical Sciences, Tehran, Iran*For correspondence: crc@sbmu.ac.ir 
diagnosis of 10 squamous cell carcinoma (2/1000 CIN and 1.2/100000 cervical cancer rate). The evaluation included the overall cervical neoplasm detection, its efficiency and the costs of this screening program (split into the fixed costs and the changing costs, costs of smear taking, costs of cytological evaluation, and costs of registration). Finally, it resulted in a new policy rule in which since year 2000, the cervical cancer screening was no longer covered by the public health services. The opportunity of screening was still provided for the women based on their own request or the health workers' (midwives, gynecologists) recommendation. It is still partly covered by the same insurance companies (M. o. Health, 2001; Allahverdipour and Emami, 2008).

The national studies showed that more than $80 \%$ of the women who were diagnosed with an invasive lesion never experienced an early detection procedure in their lifetime, or had no appropriate follow up, while some other Iranian women in central cities are over-screened due to personal demand (Karimi et al., 2010; Farajzadegan et al., 2012). The national cancer registry program, which has run since 2003, showed that cervical cancer death rate (ASR) was less than $2.6 \%$ in Iran. Meanwhile, the death rate of this cancer among the women, diagnosed with an invasive cervical cancer, is about $40 \%$ (I. M. o. Health, 2012). Some studies reported an increase in abnormal pap smear results in Iran during the past few years with 2 to 4 folds growth, compared to the previous reports (Maryam and F.M.D., 2007; Farajzadegan et al., 2012). Also among the women diagnosed with cervical cancer, HPV infection prevalence, which is the primary causal agent for cervical cancer, is $70-84 \%$. Its prevalence is $6-8 \%$ in general population (Khodakarami et al., 2012), which is lower than in many other settings, but is still higher than in some other Asian populations e.g. Pakistan, rural Vietnam (Crosbie et al., 2013).

Iran has a population of 27 million women aged 15-69 years who are at a risk for cervical cancer. Considering the potential of cervical cancer as a screen able disease we justified for developing a systematic, efficient and affordable guideline to cover majority of Iranian women population for cervical cancer screening. It should be an effective way to control cervical cancer and contribute to future considerations of the cost-effectiveness and feasibility of HPV-base vaccination.

The main object of this study was to draft a recommendation guideline for cervical cancer screening among sexually active women, based on the territorial demographic, cultural and socioeconomic data in Iran ,that could be work in other Muslim societies

\section{Materials and Methods}

This study was carried out as a joint program between cancer research center, ministry of health, and health deputy of Shahid Beheshti University of Medical Sciences through a practical guideline development protocol, searching systematically for pertinent evidence to answer eight central questions addressed in the guideline (Turner et al., 2008).

The study was approved by the Review Board of
SBMU, supported by policy council of Iranian Ministry of Health and supervised by a steering committee. We conducted a systematic review of previous studies, related to cervical cancer in Iran and reviewed the international guidelines, the result of a follow up study and the results of an expert panel discussion. Key words were picked up both for domestic and foreign search, based on the study goals.

The evidence was reviewed by two groups of experienced researchers of the cancer research center and supervised by its head who was also the head of Guideline development in Iranian Ministry of Health Policy Council. The idea behind having two groups was to minimize the failure chance of selecting and reviewing the studies.

Most of the studies were chosen from the medical literature databases like Pub MED, Science Direct, OVID, ISI, Islamic World Science Citation Center (ISC), Iranian Data base (SID) and Iranian medical journals (English and Persian). National studies were sorted into four categories; cervical cancer incidencemortality, screening, cost -effectiveness studies, cervical cancer risk factors, and HPV prevalence both in women diagnosed with cervical cancer and the healthy women. Collected data were summarized and indicated with four quality grades: good, moderate, poor and inadequate. The following step started through cervical cancer screening and prevention guidelines in eight countries, which had organized cervical cancer screening program. The results of this systematic review were formulated by the Grading of Recommendations, Assessment, Development and Evaluation (GRADE) system to determine the quality of the evidences for consideration (Schunemann et al., 2008). Seven key subjects, questioned by a research group, to find appropriate evidences for a clean and rational answer to every query were as follows: $i$ ). Is an organized cervical cancer screening program needed for Iranian women?; ii). What is the appropriate tool for the screening [Conventional Pap smear, HPV DNA testing, Liquid based cytology or visual Inspection with acetic acid (VIA)]?; iii). What is the reasonable age to begin the screening program?; $i v)$. What is the reasonable age to finish the screening program?; $v$ ). How often should the screening test be repeated ?vi). Is it necessary to call post hysterectomy and pregnant women for screening?; vii). Should Visual inspection with Acetic Acid (VIA) be used as an alternative test to pap smear in low resource location?

In order to achieve an appropriate answer, based on the evidences of literature review, a structured questionnaire was prepared to make the draft of the guideline, which contained multiple choice questions for the main question to be rated through a Likert's scale (1-5) (Malhotra and Peterson, 2006). Then, the guideline developers reviewed all the data to make a decision about which outcomes would be crucial and which would be important (the balance between the ideal and the feasiblility), and came to a final conclusion regarding the rating of the overall quality of the evidences, drafted as a strong recommendation.

For the translation the evidences into recommendations, we designed a questionnaire by the systematic review results of the national and international data which supported by sufficient evidence both grade A and B recommendations. The questionnaire was attached to a 
tabular array of systematic approach (cost effectiveness studies for different screening methods) (Table 2) (Chuck, 2010; Levin et al., 2010; Vijayaraghavan et al., 2010; Vijayaraghavan et al., 2010; Sroczynski et al., 2011; Burger et al., 2012; ; Saslow et al., 2012; van Rosmalen et al., 2012; Kulasingam, et al., 2013; Peirson et al., 2013) and has been sent via email to 40 expert (Oncologist, gynecologists, epidemiologists, midwives, physicians, Pathologists and reproductive health specialists) for their comments and ratting. After analyzing the result of this survey a recommendation for the guideline was developed. Also we considered the result of a 5 years follow up of 361 women who participated in a population base survey for incidence of HPV prevalence among Iranian women on 2008. We invited them again on 2012 for a repeated cytological test (conventional pap smear) after 6 years .The aim of this follow up study was to gather more appropriate national evidences for the cervical cancer screening program. To improve and confirm the recommendation, two technical advisory panel were conducted. The first one, that held in the Cancer Research Center ,the draft was reviewed by twelve invited experts. The second was an external panel that discussed about the draft and results of the first expert panel recommendations, we consider the number of voted for every recommendation of the expert consultants group, then appropriates recommendation took in to account. When the guideline was refined, we conducted a symposium with combination of steering committee and all leading experts who were consultants for the guideline developer team. In addition we invited representatives from Ministry of Health, Center of Disease and Cancer Control, UNFPA, stakeholders and advocacy organizations for a one day symposium. Tow week before the symposium we sent a copy of the drafted guideline for all invited experts .Symposium was held at Academic Medical Sciences of Iran. We presented the methods of the guideline development and explore the summery of the recommendation for the cervical cancer screening in
Iran. The result of the symposium discussion was analyzed and took in to account for the final version of the guideline that we written and sent to the Iran Ministry of Health for approving.

Steering committee controlled conflict of interest (COI) for all working groups concerning not having a direct or indirect relation with companies that market or sells the screening tests or devices. For the final decision panel in addition to steering committee we invited representatives from Ministry of Health, CDC, UNFPA, and advocacy organizations for a one day symposium.

The target for this guideline was the majority of women in the general population who were married, widowed or divorced. Usually unmarried females are not sexually active in Muslim Societies.

\section{Results}

For the national evidences systematic review, we found 190 full text records about cervical cancer in Iran (1971 to 2013 of which 23 articles were eligible for inclusion in the review. Among them, 13 articles were directly or indirectly related to the data needed to develop the recommendation questions (Adli, 1976; Mortazavi et al., 2002; Eftekhar et al., 2005; Tbrizi et al., 2006; Maryam and F.M.D, 2007; Noorbala and Kafaie, 2007; Allahverdipour and Emami, 2008; Esmaeili et al., 2008; Farnaz et al., 2008; Nokiani et al., 2008; Zarchi et al., 2010; Khodakarami et al., 2011; Farajzadegan et al., 2012; Khodakarami et al., 2012; Khorasanizadeh et al., 2013). We also reviewed World Health Organization (Data, 2013), IARC (Bray et al., 2013) ,GLOBOCAN report (Ferlay and Forman, 2013), Iran Ministry of Health cancer registry report (I. M. o. Health, 2012) and nine available international guidelines (Debbie et al., 2012; Lonnberg, Anttila, et al., 2012; Canadian Task Force on Preventive Health et al., 2013; Data, 2013; Giorgi Rossi and Ronco, 2013; Simonella and Canfell, 2013) (Table 1). In addition

Table 1. Cervical Cancer Screening Program in Different Countries

\begin{tabular}{|c|c|c|c|c|c|c|}
\hline Country Name & $\begin{array}{l}\text { age to Start } \\
\text { (Year) }\end{array}$ & Screening Interval & $\begin{array}{l}\text { Screening } \\
\text { Cessation }\end{array}$ & Screening Tool & HPV DNA Test & $\begin{array}{c}\text { Mortality } \\
(\mathrm{ASR}) / 100000\end{array}$ \\
\hline Australia & $18-20$ & every 2 yr & $69 \mathrm{Yr}$ & Pap Smear & yes & 0.6 \\
\hline Canada & $25-30$ & every 5 yr & $69 \mathrm{yr}$ & Pap Smear & No recommandation & 1.6 \\
\hline Europe & $22-30$ & every $3-5$ yr & $60-65$ & Pap Smear & $\begin{array}{l}\text { recomandation for } \\
\text { 30-35 Yr every } 5 \mathrm{yr}\end{array}$ & 10.5 \\
\hline Finland & 30 & every 5 yr & 60 & pap Smear & No recommandation & 1 \\
\hline Netherland & 30 & $\begin{array}{l}\text { Every } 5 \mathrm{yr} \text { for age } \\
30-49 \text { yr every } 10 \mathrm{yr} \\
\text { for age } 50-60\end{array}$ & 60 & Pap Smear & for women $\geq 30 \mathrm{yr}$ & 2.5 \\
\hline New Zealand & 20 & every 3 Yr & 70 & Pap smear & No recommandation & $1.4-2$ \\
\hline Singapore & 25 & $3 \mathrm{yr}$ & 69 & Pap Smear & No recommandation & 1.8 \\
\hline $\begin{array}{l}\text { United } \\
\text { Kingdom }\end{array}$ & 25 & $\begin{array}{c}\text { Every } 3 \text { yr for age } \\
25-49 \text { and every } 5 \text { yr } \\
\text { after } 50 \mathrm{yr}\end{array}$ & 64 & $\begin{array}{l}\text { Liquid based } \\
\text { cytology (LBC) }\end{array}$ & & 2.1 \\
\hline United State & 21 & $\begin{array}{c}\text { every } 3 \mathrm{Yr} \text { after } 30 \text { co } \\
\text { test every } 5 \mathrm{Yr}\end{array}$ & 65 & Pap Smear & $\begin{array}{l}\text { combination with } \\
\text { Pap smear from } \\
30-60\end{array}$ & Table1 \\
\hline
\end{tabular}


to the Iranian studies and international guidelines, some international articles were identified that addressed various aspects, related to the technology assessments and costeffectiveness of cervical cancer Screening (Hsairi et al., 2000; Castle et al., 2008; Castellsague et al., 2009; Arbyn et al., 2011; de Bekker-Grob et al., 2012; Ronco et al., 2012; Sankaranarayanan et al., 2012; van Rosmalen et al., 2012; Berkhof et al., 2013; Khozaim et al., 2013; Rashid et al., 2013; Rustagi et al., 2013; Xu et al., 2013).

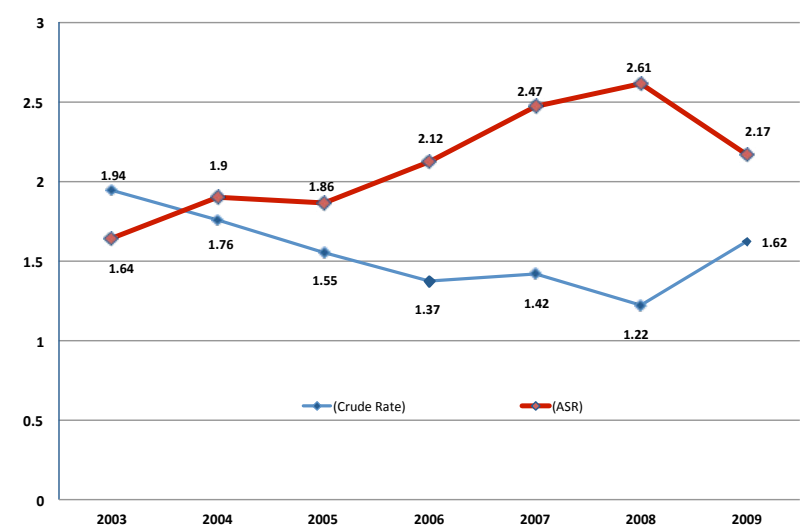

Figure 1. Estimated incidence of cervical cancer(Crud and Age Standardised Rate per 100,000) during 7 years cancer registry program
The first question was the necessity of cervical cancer screening program in Iran .Guideline developer and experts were completely agree that an organized cervical cancer screening is a necessity, as over 500 -900 new cases with invasive cervical cancer who are diagnosed every year in Iran cannot be ignored (the annual number of new cases of cervix uteri cancer was 2.4 per 100,000 women) (I. M. o. Health, 2012; Ferlay and Forman, 2013). The guideline would be applied to all women who are or have ever been married. General information about the cervical cancer situation, according to a five-year National Cancer Registry report that presented in (Figure 1). Research shows that the main risk factor such as HPV infection, and then, smoking, passive smoking, multiparity, divorce, use of oral contraceptives for more than 9 years, low socioeconomic status and husband's polygamy play an important role in incidence of cervical cancer in Iran (Esmaeili et al., 2008; Momtahen et al., 2009; Karimi et al., 2010; Allameh et al., 2011; Ghaemmaghami et al., 2012; Khodakarami et al., 2012; Haghshenas et al., 2013). The expert's high lilted that these risk factors should be considered in prevention programs.

Appropriate tool for the cervical cancer screening

We utilized the data, related to the appropriate tool for the cervical cancer screening in Iran, by

Table 2. Evidence for Tool of Cervical Cancer Screening in Iran

\begin{tabular}{|c|c|c|c|c|}
\hline Author,s & Country & $\begin{array}{l}\text { suggestion for } \\
\text { age to start }\end{array}$ & Interval & screening thechnique \\
\hline Burger (2012) & The Netherlands & 31 & 5 & HPV DNA \\
\hline Chuck (2010) & Canada & after 30 & 3 & Conventional Pap test, HPV, LBC \\
\hline De Bekker-Grob(2012 & Europe & after 30 & 5 & \\
\hline $\begin{array}{l}\text { Kulasingam (2013) } \\
\text { Saslow (2012 }\end{array}$ & USA & 21 & $\begin{array}{c}3 \text { for age } 21-29 \text { and } 5 \\
\text { for after } 30 \text { years }\end{array}$ & Cytology /HPV DNA \\
\hline Levin (2010) & China & 35 & $5(3$ time $)$ & $\begin{array}{c}\text { Conventional Pap Test, LBC Pap, } \\
\text { VILI/VIA }\end{array}$ \\
\hline Peirson (2013) & Canada & 30 & 5 & cytology test \\
\hline Scrozynski (2011) & Germany & 30 & 2 & Co-Screening \\
\hline Vijayaraghavan (2010) & USA & 30 & 30 & HPV DNA \\
\hline
\end{tabular}

Table 3. The Studies on HPV Prevalence among Healthy Iranian Women

\begin{tabular}{|c|c|c|c|c|c|c|c|c|}
\hline Author & year & $\begin{array}{l}\text { Number } \\
\text { of tested } \\
\text { women }\end{array}$ & $\begin{array}{c}\text { HPV Positive } \\
\mathrm{N}(\%)\end{array}$ & $\begin{array}{l}\text { HPV } 16 \\
\mathrm{~N}(\%)\end{array}$ & $\begin{array}{l}\text { HPV } 18 \\
\mathrm{~N}(\%)\end{array}$ & $\begin{array}{l}\text { HPV } 31 \\
\mathrm{~N}(\%)\end{array}$ & any & Study Methodology \\
\hline Khodakarami & 2012 & 825 & 7.8 & 2.1 & 0.2 & 0.6 & 4.9 & Population Base \\
\hline Yousefzadeh & 2014 & 851 & $262(31.1)$ & 7.3 & 2.8 & not reported & not reported & $\begin{array}{c}\text { Retrospective } \\
\text { among Gyn Clinic }\end{array}$ \\
\hline Safaei & 2010 & 402 & 5.5 & 2 & 0 & not reported & not reproted & $\begin{array}{c}\text { Population base } \\
\text { survey }\end{array}$ \\
\hline Ghafari & 2006 & 127 & $10(13)$ & 42 & 12.7 & not reported & not reported & $\begin{array}{c}\text { Retrospective } \\
\text { among Gyn Clinic }\end{array}$ \\
\hline Afshar & 2013 & 410 & $108(26.34)$ & 10.1 & 0 & not reported & not reported & population base \\
\hline Zandi & 2010 & 200 & 5.5 & 3.5 & 1.5 & 0 & not reported & $\begin{array}{l}\text { women who } \\
\text { attending for } \\
\text { opurtunity screening }\end{array}$ \\
\hline
\end{tabular}


Table 4. Questions Details of the Studies Regarding A Cervical Cancer Screening Program in Iran and Final Recomandation

\begin{tabular}{|c|c|c|c|}
\hline Question & Choices by GRADE rating & $\begin{array}{l}\text { Grade rating (Strong, } \\
\text { moderate, weak) }\end{array}$ & $\begin{array}{c}\text { final experts } \\
\text { Recommendation }\end{array}$ \\
\hline $\begin{array}{l}\text { Is organized cervical cancer screening a } \\
\text { requisite program for Iranian women? }\end{array}$ & Yes/No & Moderate & yes \\
\hline $\begin{array}{c}\text { What is the adequate tool for the screening } \\
\text { by considering: cost-effectiveness, } \\
\text { feasibility ,fair access? }\end{array}$ & $\begin{array}{l}\text { Conventional Pap smear, HPV } \\
\text { DNA testing, liquid based } \\
\text { cytology or visual inspection with } \\
\text { acetic acid (VIA) }\end{array}$ & Strong & $\begin{array}{l}\text { Cytology } \\
\text { test(Conventional pap } \\
\text { smear or LBC) }\end{array}$ \\
\hline $\begin{array}{c}\text { What is the reasonable time for beginning } \\
\text { the screening program? }\end{array}$ & $\begin{array}{l}3 \text { years after marriage at } 21,25 \text { or } \\
30 \text { years }\end{array}$ & Moderate & 30 years \\
\hline $\begin{array}{l}\text { What is the reasonable time to stop the } \\
\text { screening program? }\end{array}$ & Ages: $59,65,69$ or 75 years & Strong & 69 years \\
\hline $\begin{array}{l}\text { At what time interval should the screening } \\
\text { be repeated? }\end{array}$ & Annually, every 3,5 years & Moderate & every 5 years \\
\hline $\begin{array}{l}\text { Is it necessary to invite post hysterectomy } \\
\text { and pregnant women for screening? }\end{array}$ & Yes/No & strong & No \\
\hline $\begin{array}{l}\text { Could Visual inspection with Acetic } \\
\text { Acid(VIA) be used as an alternative test to } \\
\text { pap smear in low resource location? }\end{array}$ & Yes/No & strong & Yes \\
\hline $\begin{array}{l}\text { Is it necessary HPV vaccination come to } \\
\text { the national guidline }\end{array}$ & Yes/No & Moderated & No \\
\hline
\end{tabular}

consideration of national studies, which determined cost-effectiveness, sensitivity, specificity and accuracy of different technologies for cervical cancer screening (Ghaemmaghami et al., 2004; Eftekhar et al., 2005; Nokiani et al., 2008; Karimi et al., 2011; Khodakarami et al., 2011), World Health organization and international guidelines (Table 1) (David, 2010; Debbie et al., 2012; Canadian Task Force on Preventive Health et al., 2013; Data, 2013; Lowe, 2013; Simonella and Canfell, 2013). Although many evidences show that HPV test has a higher sensitivity and adding an HPV test to cytology (Co testing), or doing HPV as a primary screen followed by triage by cytology, increases detection of cervical precancerous lesions (Aoki et al., 2012; Trope et al., 2012; Untiet et al., 2013; Abraham and Stenger, 2014). Nevertheless, the HPV test has lower specificity and more expensive than cytology (van Rosmalen et al., 2012). Therefore we focused on a program that makes screening available all over the country and its feasibility, manageability and cost beneficence for the National Health System (Iran spends $\$ 346$ per capita (USD) on health care) (Bank, 2013). The cytological (PAP smear) method got a good grade as a simple and low cost test for the cervical cancer screening in Iran.

We came to the conclusion that the conventional Pap smear test provides a suitable balance between the benefits and harms in a country with low HPV and cervical cancer incidence (Table 3) and a small budget for financing the health screening programs. Expert panel indicated that if liquid-Based Cytology (LBC) method is available, LBC can be a cost-effective alternative for the Pap smear in preparation of cervical cells sampling, which may make the slides easier to read, reduce the rate of inadequate smear tests, improve efficiency of handling laboratory samples and result in an increased laboratory productivity.
It allows for easy combination with HPV testing in the future.

Age to start and lay off the screening

Cervical cancer screening for Iranian women should start at the age of 30 years and stop at the age of 69 years. The choice of such age points is rational and evidence-based with regard to the mean age at which a woman gets married for the first time (23.5 years), international evidences (Table 3) (Chuck, 2010; Levin et al., 2010; Vijayaraghavanet al., 2010; Sroczynski et al., 2011; de Bekker-Grob et al., 2012; Burger et al., 2012; Kauffman et al., 2013; Kulasingam et al., 2013; Peirson et al., 2013), prevalence and the mean age of diagnosis of cervical cancer among Iranian women that is 53.5 years (Karimi et al., 2010; Ghaemmaghami et al., 2012; I. M. o. Health, 2012) and the age recommended by WHO to begin cervical cancer screening (Data, 2013).

\section{Screening interval}

The committee recommended screening interval of every 5 years, and a back up by an adequate recall. Women with negative tests will be invited for rescreening by the five-year interval. Screening should continue with a 15 year interval after three five- year period with negative Pap tests. Rational and evidence for this screening interval was determined by the review of the international guidelines and recent meta analysis studies (Hamashima et al., 2010; Lonnberg et al., 2012; Canadian Task Force on Preventive Health et al., 2013; Kulasingam et al., 2013; Peirson et al., 2013), and WHO recommendation (Data, 2013). Also,we looked at the cytological results of 328 healthy women aged 25-65 years who already interned in an HPV prevalence survey with 825 samples in 2007-2008.We followed up the women who accepted our recall for a Pap smear test 5 years after the HPV survey (Khodakarami et 
al., 2012). The laboratory proved four ASCUS, one LSIL, four inadequate and the rest of 319 women with a normal cytology result in its report. These results were actually used as a rational evidence to make a decision on screening interval. we also considered the national health possibility and profitability for a comprehensive national program of cervical cancer prevention.

Screening during pregnancy and post hysterectomy. Evidences for the screening during pregnancy and post hysterectomy were confirmed expert panel idea and highlighted that cervical cancer screening is not a necessity for women who had a total hysterectomy due to a noncancerous condition. Expert panel members believed that pregnant women do not need screening during pregnancy, except the cases with compulsory screening for whom collecting cervical cell smear by Cyto Brush should be avoided (soaking a cotton swab is the preferred sampling technique). (Debbie et al., 2012). Related to question 7 of the study: Should Visual inspection with Acetic Acid (VIA) be used as an alternative test to pap smear in low resource location? Three national evidences help to expert panel to approve VIA for rural area that may have not access to pap smear facility.

\section{Discussion}

As cervical cancer is preventable, early detectable and is potential for treatment of precancerous lesions, its screening, is an excellent opportunity, even in a region with relatively low incidence. Previous cervical cancer screening program in Iran was an edited copy of the US guideline, modified by a national expert panel. This is the first recommendation for a guideline, that developed by national evidences and an international guideline systematic review. During the review process, we found that national data did not have adequate information to get high quality evidences, therefore, guideline developers suggested giving an appropriate reply to the proposed questions through reviewing international evidences and guidelines too. We reviewed international guidelines of the countries that have successful outcome for control cervical cancer incidence by an organized screening program ,such as Australia (Simonella and Canfell, 2013), Canada (Canadian Task Force on Preventive Health et al., 2013), Europe (Arbyn et al., 2010) Finland (Lonnberg, Nieminen, Luostarinen and Anttila, 2013), Netherland (van Rosmalen et al., 2012), New Zealand (Simonella and Canfell, 2013), Singapore(Jin, Louange, Chow, and Fock, 2013), United Kingdom (Duggan, 2012), USA (Karjane and Chelmow, 2013; Kulasingam et al., 2013), and involved experts and the stakeholders for a better solution. The role of opportunity cervical cancer screening that has already been proven in Iran is not clear for reducing the mortality of the cervical cancer. To reduce the mortality from cervical cancer, development an appropriate screening program and advisable management are required. In addition, to achieve its aims, a quality assurance system should be considered. The effects of new technologies, including liquid-based cytology and HPV testing, must be evaluated at the community level in Iran.

Some study indicated that LBC is not expected to increase sensitivity (Confortini et al., 2010) and the others belive that liquid-based cytology is expected to decrease unsatisfactory samples compared with conventional cytology. The US Food and Drug Administration (FDA) for the first time approved a Human Papilloma Virus (HPV) test for use as a first-line primary screening test for cervical cancer screening in women 25 and older (Abraham and Stenger, 2014). Also the result of a recent study in European Union shown that HPV-based screening would provided a better protection against invasive cervical cancer compared with cytology and support initiation of HPV-based screening from age 30 years with at least 5 years intervals (Ronco et al., 2014). According the result of final round of experts panel discussion ,they came to the conclusion that in countries such as Iran with limited resources, mass screening with HPV test is not best choices for now. However for an effective evaluation of the recommendation, we were advised to design a pilot study within the family physician program (that is now running in Fars and Mazandaran provinces of Iran as a pilot study). The family physician pilot program would be an opportunity to evaluate this recommendation as a guideline for cervical cancer screening within public health services and can be updated further by new national and international evidences. We should proceed to act collaboratively with national health system to create the models, protocols, and implement issues to develop an efficient, cost-effective recall and a follow-up system for cervical cancer screening that Government would be convinced to invest appropriately for it.

We recommended an organized population- based program for average risk women, aiming at controlling the cervical cancer in Iran (Table 4). According this recommendation the screening with cytology test would be start at ages 30 among women who are married The interval is 5 years and the end of screening ages is 69 years we expect that application of this recommendation would result in a lower incidence of cervical cancer in Iran and other Muslim countries (EMRO, Middle East, and west Asia). In parallel developing awareness and empowerment programs on HPV infection as a sexual transmitted disease by the aim of the disease prevention and control for youth, could come into account and make the behavior, culture, faith and religion issues as an asset for set up the screening guideline. By provision of an online registration software and creation of a permanent facility for regular monitoring, rating and timely updating of this guideline, we can revise the present version to a better one that will be developed completely by national and regional data in future. It is expected that this recommendation would permit less wasteful cervical screening, while take the opportunity to National Health System towards ensuring adequate coverage of high-risk women. We hope to achieve further improvements to better technology for cervical lesions early detection and prevention, such as HPV DNA test and HPV vaccination for all eligible women.

\section{Acknowledgements}

This article is a part of the $\mathrm{PhD}$ thesis of Dr Nahid Khodakarami. We wish to express our particular thanks to 
Dr Gary Clifford from IARC, for his great contribution and a number of experts who generously gave their time to fill the survey questionnaires, prepare think pieces, participate in meetings and provide comments on the drafts of the recommendation. Special thanks go to the members of the expert panel. UNFPA and all Cancer Research Center staffs for their great contribution.

\section{References}

Abraham J, Stenger M (2014). Cobas HPV test for first-line screening for cervical cancer. J Community Support Oncol, 12, 156-7.

Adli AG (1976). [Results of 83,621 cytopathologic examinations of cervico-vaginal smears]. Arch Anat Cytol Pathol, 24, 395-6.

Allahverdipour H, Emami A (2008). Perceptions of cervical cancer threat, benefits, and barriers of Papanicolaou smear screening programs for women in Iran. Women Health, 47, 23-37.

Allameh T, Moghim S, Asadi-Zeidabadi M (2011). A survey on the prevalence of high-risk subtypes of human papilloma virus among women with cervical neoplasia in Isfahan university of medical science. Arch Gynecol Obstet, 284, 1509-13.

Aminisani N, Armstrong BK, Canfell K (2012). Cervical cancer screening in Middle Eastern and Asian migrants to Australia: a record linkage study. Cancer Epidemiol, 36, 394-400.

Aoki D, Saito E, Tominaga E (2012). [Cervical cancer screening]. Gan To Kagaku Ryoho, 39, 23-26.

Arbyn M, Anttila A, Jordan J, et al (2010). European Guidelines for Quality Assurance in Cervical Cancer Screening. Second edition--summary document. Ann Oncol, 21, 448-458.

Arbyn M, Castellsague X, de Sanjose S, et al (2011). Worldwide burden of cervical cancer in 2008. Ann Oncol, 22, 2675-86.

Bank World (2013). Health expenditure per capita (current US\$) (data Indicators). from World Bank http://data.worldbank. org/indicator/SH.XPD.PCAP/countries

Behmard S, Taherzadeh D, Gondos, B (1977). Cytologic screening for cervical cancer in southern Iran. Acta Cytol, 21, 432-4.

Berkhof J, Bogaards JA, Demirel E, et al (2013). Costeffectiveness of cervical cancer prevention in central and eastern europe and central Asia. Vaccine, 31, 71-79.

Bray F, Ren JS, Masuyer E, Ferlay J (2013). Global estimates of cancer prevalence for 27 sites in the adult population in 2008. Int J Cancer, 132, 1133-45.

Burger EA, Ortendahl JD, Sy S, Kristiansen IS, Kim JJ (2012). Cost-effectiveness of cervical cancer screening with primary human papillomavirus testing in Norway. Br J Cancer, 106, 1571-8.

Canadian Task Force on Preventive Health, Care, Pollock S, et al (2013). Recommendations on screening for cervical cancer. CMAJ, 185, 35-45.

Castellsague X, Remy V, Puig-Tintore LM, et al (2009). Epidemiology and costs of screening and management of precancerous lesions of the cervix in Spain. J Low Genit Tract Dis, 13, 38-45.

Castle PE, Sideri M, Jeronimo J, Solomon D, Schiffman M (2008). Risk assessment to guide the prevention of cervical cancer. J Low Genit Tract Dis, 12, 1-7.

Chuck A (2010). Cost-effectiveness of 21 alternative cervical cancer screening strategies. Value Health, 13, 169-79.

Confortini M, Bergeron C, Desai M, et al (2010). New technologies for cervical cancer screening study cytology, group. accuracy of liquid-based cytology: comparison of the results obtained within a randomized controlled trial (the new technologies for cervical cancer screening study) and an external group of experts. Cancer Cytopathol, 118, 203-8.

Crosbie EJ, Einstein MH, Franceschi S, Kitchener HC (2013). Human papillomavirus and cervical cancer. Lancet, 382, 889-99.

Data, WHO Library Cataloguing-in-Publication (2013). WHO guidelines for screening and treatment of precancerous lesions for cervical cancer prevention (G. ink Ed.).

David Luesley, Simon Leeson (2010). Colposcopy and programme management. (20). fulwood house old fulwood road sheffield UK: NHS cancer screening programmes Retrieved from http://www.cancerscreening.nhs.uk/cervical/ publications/nhscsp20.pdf.

de Bekker-Grob EW, de Kok IM, Bulten J, et al (2012). Liquid-based cervical cytology using ThinPrep technology: weighing the pros and cons in a cost-effectiveness analysis. Cancer Causes Control, 23, 1323-31.

Duggan MA (2012). Commentary on "Cervical cancer screening in England: the past, present, and future": a comparison with Canada. Cancer Cytopathol, 120, 97-101.

Eftekhar Z, Rahimi-Moghaddam P, Yarandi F, Brojerdi R (2005). Accuracy of visual inspection with acetic acid (VIA) for early detection of cervical dysplasia in Tehran, Iran. Asian Pac J Cancer Prev, 6, 69-71.

Esmaeili M, Bonyadi M, Dastranj A, et al (2008). HPV typing in women with cervical precancerous and cancerous lesions in northwestern Iran. Gynecol Obstet Invest, 66, 68-72.

Farajzadegan Z, Nourbakhsh SF, Mostajeran M, Loghmani A (2012). Cervical cancer screening status in 35 to 60 year-old women in Isfahan, Iran. J Isfahan Med School, 30, 1542-9.

Farnaz AH, Ebrahim E, Bita K (2008). Pathologic characteristics, type of treatment and follow up of patients with uterine cervical carcinoma referred to the radiation oncology department, cancer institute, imam khomeini hospital,tehran, Iran, 1995-2001. Asian Pac J Cancer Prev, 9, 86-88.

ferlay J, Soerjomataram I, Ervik M, et al (2013). GLOBOCAN 2012,Cancer Incidence and Mortality Worldwide. Globacon2012. (11). from IARC http://globocan.iarc.fr/ Pages/fact_sheets_population.aspx

Forman D, de Martel C, Lacey CJ, et al (2012). Global burden of human papillomavirus and related diseases. Vaccine, 30, $12-23$.

Ghaemmaghami F, Behtash N, Modares Gilani M, et al (2004). Visual inspection with acetic acid as a feasible screening test for cervical neoplasia in Iran. Int J Gynecol Cancer, 14, 465-9.

Ghaemmaghami F, Saleh-Gargari S, Sahebdel B, Behtash N, Samiei F (2012). Risk factors and clinical aspects of recurrent invasive cervical carcinoma. J Obstet Gynaecol India, 62, 674-8.

Giorgi Rossi P, Ronco G (2013). The present and future of cervical cancer screening programmes in Europe. Curr Pharm Des, 19, 1490-7.

Habibi A (1965). Cancer in iran. a survey of the most common cases. J National Cancer Inst, 34, 553-69.

Habibi A (1970). Cancer in Iran. Statistical review on 28,000 cases. Pathol Microbiol (Basel), 35, 181-3.

Habibi A (1971). Cancer in Iran. malignant tumors of the female genitalia. Int Surg, 56, 13-7.

Haghshenas M, Golini-Moghaddam T, Rafiei A, et al (2013). Prevalence and type distribution of high-risk human papillomavirus in patients with cervical cancer: a populationbased study. Infect Agent Cancer, 8, 20.

Hamashima, C, Aoki, D, Miyagi, E, et al (2010). Japanese research group for development of cervical cancer screening, guidelines. The Japanese guideline for cervical cancer 
screening. Jpn J Clin Oncol, 40, 485-502.

Health, Iran Ministry of (2012). Iran Cancer Report 1388 (CDC, Trans.). Iran: Cancer Registration Office.

Health, Ministry of (2001). National Health Program. Tehran: Population and Family Health Office of Ministry of health Retrieved from http://www.arums.ac.ir/opencms/export/ sites/default/fa/scientometric/downloads/Health_programs. pdf.

Hsairi M, Fakhfakh R, Ghyoula M, Ben Abdallah M, Achour, N (2000). [Cost effectiveness of cervical cancer screening strategies in Tunisia]. Tunis Med, 78, 557-61.

Jin AZ, Louange EC, Chow KY, Fock CW (2013). Evaluation of the national cervical cancer screening programme in Singapore. Singapore Med J, 54, 96-101.

Karimi Zarchi M, Akhavan A, Fallahzadeh H, et al (2010). Outcome of cervical cancer in Iranian patients according to tumor histology, stage of disease and therapy. Asian Pac J Cancer Prev, 11, 1289-91.

Karimi Zarchi M, Akhavan A, Gholami H, et al (2010). Evaluation of cervical cancer risk-factors in women referred to Yazd-Iran hospitals from 2002 to 2009. Asian Pac J Cancer Prev, 11, 537-8.

Karimi Zarchi M, Binesh F, Kazemi Z, et al (2011). Value of colposcopy in the early diagnosis of cervical cancer in patients with abnormal pap smears at Shahid Sadoughi hospital, Yazd. Asian Pac J Cancer Prev, 12, 3439-41.

Karjane N, Chelmow D (2013). New cervical cancer screening guidelines, again. Obstet Gynecol Clin North Am, 40, 211-23.

Kauffman RP, Griffin SJ, Lund JD, Tullar PE (2013). Current recommendations for cervical cancer screening: do they render the annual pelvic examination obsolete? Med Princ Pract, 22, 313-22.

Khodakarami N, Clifford GM, Yavari P, et al (2012). Human papillomavirus infection in women with and without cervical cancer in Tehran, Iran. Int J Cancer, 131, 156-61.

Khodakarami N, Farzaneh F, Aslani F, Alizadeh K (2011). Comparison of pap smear, visual inspection with acetic acid, and digital cervicography as cervical screening strategies. Arch Gynecol Obstet, 284, 1247-52.

Khorasanizadeh F, Hassanloo J, Khaksar N, et al (2013). Epidemiology of cervical cancer and human papilloma virus infection among Iranian women - analyses of national data and systematic review of the literature. Gynecol Oncol, 128, 277-81.

Khozaim K, Orang'o E, Christoffersen-Deb A, et al (2013). Successes and challenges of establishing a cervical cancer screening and treatment program in western Kenya. Int $J$ Gynaecol Obstet.

Kulasingam SL, Havrilesky LJ, Ghebre R, Myers ER (2013). Screening for cervical cancer: a modeling study for the us preventive services task force. J Low Genit Tract Dis, 17, 193-202.

Levin CE, Sellors J, Shi JF, et al (2010). Cost-effectiveness analysis of cervical cancer prevention based on a rapid human papillomavirus screening test in a high-risk region of China. Int J Cancer, 127, 1404-11.

Lonnberg, S, Anttila, A, Luostarinen, T, Nieminen, P. (2012). Age-specific effectiveness of the Finnish cervical cancer screening programme. Cancer Epidemiol Biomarkers Prev, 21, 1354-61.

Lonnberg, S, Nieminen, P, Luostarinen, T, Anttila, A. (2013). Mortality audit of the Finnish cervical cancer screening program. Int J Cancer, 132, 2134-40.

Lowe NK (2013). Cervical cancer screening guidelines 2012. J Obstet Gynecol Neonatal Nurs, 42, 1-2.

Malhotra Naresh K, Peterson Mark (2006). Basic marketing research: a decision-making approach $\left(2^{\text {nd }}\right.$ ed.). Upper saddle river, $n . j .:$ pearson/prentice hall.

Maryam Afrakhteh, Nahid Khodakarami, Afshin Moradi, et al (2007). A Study of 13315 Papanicolau smear diagnoses in shohada hospital. J Family Reprod Health, 1.

Momtahen S, Kadivar M, Kazzazi AS, Gholipour F (2009). Assessment of gynecologic malignancies: a multi-center study in Tehran (1995-2005). Indian J Cancer, 46, 226-30.

Mortazavi S, Zali M, Raoufi M, et al (2002). The prevalence of human papillomavirus in cervical cancer in Iran. Asian Pac J Cancer Prev, 3, 69-72.

Nokiani FA, Akbari H, Rezaei M, Madani H, Ale Agha ME (2008). Cost--effectiveness of pap smear in Kermanshah, Iran. Asian Pac J Cancer Prev, 9, 107-10.

Noorbala MT, Kafaie P (2007). Analysis of 15 years of skin cancer in central Iran (Yazd). Dermatol Online $J, \mathbf{1 3}, 1$.

Peirson L, Fitzpatrick-Lewis D, Ciliska D, Warren R (2013). Screening for cervical cancer: a systematic review and metaanalysis. Syst Rev, $2,35$.

Rashid RM, Dahlui M, Mohamed M, Gertig D (2013). Adapting the Australian system: is an organized screening program feasible in Malaysia?--an overview of cervical cancer screening in both countries. Asian Pac J Cancer Prev, 14, 2141-6.

Ronco G, Biggeri A, Confortini M, et al (2012). [Health technology assessment report: HPV DNA based primary screening for cervical cancer precursors]. Epidemiol Prev, 36, 1-72.

Ronco G, Dillner J, Elfstrom KM, et al (2014). Efficacy of HPVbased screening for prevention of invasive cervical cancer: follow-up of four European randomised controlled trials. Lancet, 383, 524-32.

Rustagi AS, Kamineni A, Weiss NS (2013). Point: cervical cancer screening guidelines should consider observational data on screening efficacy in older women. Am J Epidemiol, 178, 1020-2.

Sankaranarayanan R, Nessa A, Esmy PO, Dangou, JM (2012). Visual inspection methods for cervical cancer prevention. Best Pract Res Clin Obstet Gynaecol, 26, 221-32.

Saslow D, Solomon D, Lawson HW, et al (2012). American cancer society, american society for colposcopy and cervical pathology, and american society for clinical pathology screening guidelines for the prevention and early detection of cervical cancer. J Low Genit Tract Dis, 16, 175-204.

Saslow D, Solomon D, Lawson HW, et al (2012). American cancer society, American Society for colposcopy and cervical pathology, and American Society for clinical pathology screening guidelines for the prevention and early detection of cervical cancer. CA Cancer J Clin, 62, 147-72.

Schunemann HJ, Oxman AD, Brozek J, et al (2008). GRADE: assessing the quality of evidence for diagnostic recommendations. ACP J Club, 149, 2.

Simonella L, Canfell K (2013). The impact of a two- versus three-yearly cervical screening interval recommendation on cervical cancer incidence and mortality: an analysis of trends in Australia, New Zealand, and England. Cancer Causes Control, 24, 1727-36.

Sroczynski G, Schnell-Inderst P, Muhlberger N, et al (2011). Cost-effectiveness of primary HPV screening for cervical cancer in Germany--a decision analysis. Eur J Cancer, 47, 1633-46.

Tbrizi AD, Alidazeh M, Melli MS, Jafari M, Madarek E (2006). Incidence rate of cervical cancer and precancerous lesions in East Azarbayjan, Iran. Asia Pac J Clin Oncol, 2, 87-90.

Trope A, Sjoborg KD, Nygard M, et al (2012). Cytology and human papillomavirus testing 6 to 12 months after ASCUS or LSIL cytology in organized screening to predict highgrade cervical neoplasia between screening rounds. J Clin 
Microbiol, 50, 1927-35.

Turner T, Misso M, Harris C, Green S (2008). Development of evidence-based clinical practice guidelines (CPGs): comparing approaches. Implement Sci, 3, 45.

United States. Department of health and human services. (2001). healthy people 2010 : understanding and improving health (Rev. ed.). Boston: Jones and Bartlett Publishers.

Untiet S, Schmidt N, Low N, Petignat P (2013). [Cervical cancer screening in Switzerland - current practice and future challenges]. Ther Umsch, 70, 223-30.

van Rosmalen J, de Kok IM, van Ballegooijen M (2012). Costeffectiveness of cervical cancer screening: cytology versus human papillomavirus DNA testing. BJOG, 119, 699-709.

Vijayaraghavan A, Efrusy, MB, Goodman KA, Santas CC, Huh WK (2010). Cost-effectiveness of using human papillomavirus 16/18 genotype triage in cervical cancer screening. Gynecol Oncol, 119, 237-42.

Vijayaraghavan A, Efrusy, MB, Mayrand MH, Santas CC, Goggin P (2010). Cost-effectiveness of high-risk human papillomavirus testing for cervical cancer screening in Quebec, Canada. Can J Public Health, 101, 220-5.

$\mathrm{Xu} \mathrm{H}$, Zhao FH, Gao XH, et al (2013). [Cost-effectiveness analysis on the once-in-a-lifetime cervical cancer screening program for women living in rural and urban areas of China]. Zhonghua Liu Xing Bing Xue Za Zhi, 34, 399-403.

Zarchi MK, Akhavan A, Gholami H, et al (2010). Evaluation of cervical cancer risk-factors in women referred to Yazd-Iran hospitals from 2002 to 2009. Asian Pac J Cancer Prev, 11, 537-8. 